\title{
The relationship between the reporting of euphoria events and early treatment responses to pregabalin: an exploratory post-hoc analysis
}

This article was published in the following Dove Press journal:

Journal of Pain Research

\author{
Bruce Parsons' \\ Rainer Freynhagen ${ }^{2,3}$ \\ Stephan Schug ${ }^{4,5}$ \\ Ed Whalen' \\ Marie Ortiz' \\ Pritha Bhadra Brown' \\ Lloyd Knapp ${ }^{6}$
}

'Pfizer Inc, New York, NY, USA; ${ }^{2}$ Department of Anesthesiology, Critical Care Medicine, Pain Therapy \& Palliative Care, Pain Center Lake Starnberg, Benedictus Hospital, Tutzing, Germany; ${ }^{3}$ Department of Anesthesiology, Klinikum rechts der Isar, Technische Universität München, Munich, Germany; ${ }^{4}$ Discipline of Anaesthesiology and Pain Medicine, Medical School, University of Western Australia, Perth, WA, Australia; ${ }^{5}$ Department of Anaesthesia and Pain Medicine, Royal Perth Hospital, Perth, WA, Australia; ${ }^{6}$ Pfizer Inc, Groton, CT, USA
Correspondence: Bruce Parsons Pfizer Inc, 235 East 42nd Street, New York, NY, USA

Tel + I 2125731649

Email bruce.parsons@pfizer.com
Background: Euphoria is a complex, multifactorial problem that is reported as an adverse event in clinical trials of analgesics including pregabalin. The relationship between the reporting of euphoria events and pregabalin early treatment responses was examined in this exploratory post-hoc analysis.

Methods: Data were from patients with neuropathic or non-neuropathic chronic pain enrolled in 40 randomized clinical trials, who received pregabalin $(75-600 \mathrm{mg} /$ day $)$ or placebo. Reports of treatment-emergent euphoria events were based on the Medical Dictionary of Regulatory Activities preferred term "euphoric mood". Prevalence rates of euphoria events overall and by indication were assessed. Post-treatment endpoints included $\geq 30 \%$ improvements in pain and sleep scores up to 3 weeks as well as a $\geq 1$-point improvement in daily pain score up to 11 days after treatment.

Results: 13,252 patients were analyzed; $8,501(64.1 \%)$ and 4,751 (35.9\%) received pregabalin and placebo, respectively. Overall, $1.7 \%(n=222)$ of patients reported euphoria events. Among pregabalin-treated patients, a larger proportion who reported euphoria events achieved an early pain response compared with those who did not report euphoria (30\% pain responders in week 1 with euphoria events [43.0\%], without euphoria events [24.2\%]). Results were similar for weeks 2 and 3. For Days 2-11, a larger proportion of pregabalin-treated patients with (relative to without) euphoria events were 1-point pain responders. Findings were similar in pregabalintreated patients for sleep endpoints $(30 \%$ sleep responders in week 1 with euphoria events [50.7\%], without euphoria events [36.1\%]). Similar results were found for weeks 2 and 3 . Patients who received placebo showed similar patterns, although the overall number of them who reported euphoria events was small $(\mathrm{n}=13)$.

Conclusion: In patients who received pregabalin for neuropathic or non-neuropathic chronic pain, those who experienced euphoria events may have better early treatment responses than those who did not report euphoria events.

Keywords: euphoria, pain, pregabalin, sleep

\section{Introduction}

Euphoria is often perceived as a signal of potential substance abuse or addiction and has been described as an exaggerated feeling of physical and emotional well-being and optimism not consistent with apparent stimuli or events. ${ }^{1-4}$ It has been reported as an adverse event (AE) in clinical trials of medications that act on the central nervous system including analgesics. ${ }^{2,3}$ Feelings of euphoria can contribute to the abuse of prescription drugs, as illustrated by the rise in recent years of the misuse of prescription opioids in the US population, where there was a $140 \%$ increase in 
prescription drug misuse from 7.8 million in 1992 to 15.1 million in $2003 .^{5}$ However, euphoria is a complex multifactorial phenomenon that is not well understood. For instance, euphoria events occur in clinical trials of some medications such as selective serotonin reuptake inhibitors and corticosteroids, which are known not to be abused for psychotropic purposes. ${ }^{6-8}$ Moreover, many prescription drugs with significant abuse potential, such as benzodiazepines, are not typically associated with euphoria in clinical trials. ${ }^{9}$ Euphoria may also be reported in patients who receive placebo in some clinical trials. ${ }^{10}$ One additional complexity that has not been explored is the potential relationship between the reporting of euphoria events and treatment responses.

Pregabalin is an $\alpha 2 \delta$ calcium channel subunit ligand and analgesic, ${ }^{11-14}$ indicated in multiple countries for the treatment of peripheral or central neuropathic pain $(\mathrm{NeP})$ and fibromyalgia, as well as generalized anxiety disorder (GAD) and partial-onset seizures. ${ }^{10,15}$ In placebo-controlled randomized clinical trials, $4 \%$ of patients who received pregabalin reported euphoria events (defined by the preferred term "euphoric mood" using the Medical Dictionary for Regulatory Activities [MedDRA], version 19.0), with incidences varying across indications, while $1 \%$ of patients who received placebo also reported euphoria events. ${ }^{6}$

Because of the large number of patients who have participated in clinical studies of pregabalin, an opportunity exists to examine possible links between the reporting of euphoria events and treatment responses. In this exploratory post-hoc analysis of data from 40 placebocontrolled clinical trials, the objective was to assess the relationship between reported euphoria events and early treatment responses (pain and sleep) to pregabalin in patients with NeP or non-NeP.

\section{Materials and methods}

\section{Included studies}

The Pfizer database of pregabalin clinical studies was searched for studies conducted in patients with peripheral or central $\mathrm{NeP}$, or non-NeP. Studies were excluded if they analyzed patients who: were healthy volunteers, had postoperative pain, underwent experimental procedures that may have induced pain, or were primarily enrolled for functional magnetic resonance imaging. Across all studies, patients were excluded if they experienced any severe acute or chronic medical or psychiatric condition(s), were receiving prespecified concomitant medication(s) - that may have been different in the individual studies —or illicit drug(s), or exhibited any other factors that could potentially increase the risk associated with study participation or would interfere with the interpretation of the study results. In total, 40 randomized, placebo-controlled clinical studies of pregabalin efficacy and safety were identified (Table 1). Pain conditions in these analyses included diabetic peripheral neuropathy (DPN, 13 studies); ${ }^{16-24}$ postherpetic neuralgia (PHN, eight studies); ${ }^{25-30}$ posttraumatic peripheral NeP (PT pNeP, two studies); ${ }^{31,32}$ combined DPN/PHN (two studies); ${ }^{33,34}$ combined DPN/PHN/PT pNeP (one study); ${ }^{35} \mathrm{NeP}$ due to spinal cord injury (SCI, two studies) $;^{36,37}$ fibromyalgia (FM, seven studies); ${ }^{38-44}$ chronic low back pain (CLBP, two studies); osteoarthritis (OA, one study); and $\mathrm{NeP}$ associated with HIV neuropathy (HIV NeP, two studies). ${ }^{45,46}$ Nine studies are unpublished (four in DPN, two in PHN, two in CLBP, one in OA). Twenty-three studies have ClinicalTrial.gov identifiers: NCT00156078; NCT00159679; ${ }^{20}$ NCT00143156; NCT00 $553475 ;{ }^{21}$ NCT01332149; ${ }^{22}$ NCT01455415; ${ }^{23}$ NCT01474 $772 ;{ }^{24}$ NCT00159666; ${ }^{28}$ NCT00394901; ${ }^{29}$ NCT01455428; ${ }^{30}$ NCT00292188; ${ }^{31}$ NCT01701362; ${ }^{32}$ NCT00301223; ${ }^{34}$ NCT0 $0141219 ; ;^{35}$ NCT00407745; ${ }^{37}$ NCT00645398; ${ }^{39}$ NCT0023 0776; ${ }^{40}$ NCT00333866; ${ }^{41}$ NCT00883740; ${ }^{42}$ NCT008301 $67 ;^{43}$ NCT01432236; ${ }^{44}$ NCT00232141; ${ }^{45}$ NCT01049217. ${ }^{46}$

The remaining studies were not registered at ClinicalTrials. gov because they pre-dated the requirement for clinical trial registration.

The dates of the studies ranged between March 1998 and August 2015. Pregabalin was administered in doses of 75-600 mg/day (either fixed or flexible dosing). Treatment duration ranged from 4 to 16 weeks. All of the original studies were conducted in accordance with the Declaration of Helsinki and/or Good Clinical Practice Guidelines from the International Conference on Harmonisation and were approved by the institutional review board or ethics committee of each participating center. Each patient or their legal guardian or representative provided written informed consent to participate in the study. No new patients were recruited for this analysis.

\section{Capturing of euphoria events as adverse events}

Investigators were responsible for reporting treatment-emergent AEs in the original studies, including severity and potential relationship to study medication. For the purpose of this analysis, the reporting of euphoria events was coded using the preferred term "euphoric mood" (code 10015535 of the MedDRA, version 19.0). The present study did not consider 
Table I Studies included in the analysis

\begin{tabular}{|c|c|c|c|c|}
\hline Study & Indication(s) & $\begin{array}{l}\text { Treatment Duration } \\
\text { (weeks) }\end{array}$ & $\begin{array}{l}\text { Safety Population } \\
(\mathbf{N})^{a}\end{array}$ & $\begin{array}{l}\text { Pregabalin Doses } \\
\text { (mg/day) }\end{array}$ \\
\hline Richter et al $2005^{16}$ & DPN & 6 & 246 & 150,600 \\
\hline Lesser et al $2004^{17}$ & DPN & 5 & 337 & $75,300,600$ \\
\hline $1008-040$ & DPN & 8 & 167 & 600 \\
\hline Rosenstock et al $2004^{18}$ & DPN & 8 & 146 & 300 \\
\hline Tölle et al $2008^{19}$ & DPN & 12 & 395 & $150,300,600$ \\
\hline $1008-173$ & DPN & 12 & 147 & $150,300,600$ \\
\hline A008I030 (NCT00I56078) & DPN & 12 & 406 & $150-600$ \\
\hline Arrezo et al $2008^{20}$ (NCTO0I59679) & DPN & 13 & 167 & 600 \\
\hline A008I07I (NCT00I43I56) & DPN & 13 & 456 & 300,600 \\
\hline Satoh et al 201 I 21 (NCT00553475) & DPN & 13 & 314 & 300,600 \\
\hline Mu et al $2018^{22}$ (NCT0I332I49) & DPN & 9 & 622 & 300 \\
\hline 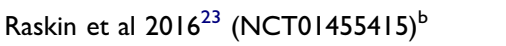 & DPN & 6 & 301 & $150-300$ \\
\hline Huffman et al $2015^{24}$ (NCTOI474772) $^{\mathrm{b}}$ & DPN & 6 & 203 & $150-300$ \\
\hline $1008-030$ & $\mathrm{PHN}$ & 5 & 255 & 75,150 \\
\hline Sabatowski et al $2004^{25}$ & PHN & 8 & 238 & 150,300 \\
\hline Dworkin et al $2003^{26}$ & PHN & 8 & 173 & 300,600 \\
\hline $1008-132$ & PHN & 12 & 216 & $150,300,600$ \\
\hline van Seventer et al $2006^{27}$ & $\mathrm{PHN}$ & 13 & 368 & $150,300,600$ \\
\hline Stacey et al $2008^{28}$ (NCT00I59666) & PHN & 4 & 269 & $300,150-600$ \\
\hline Ogawa et al $2010^{29}$ (NCT0039490I) & PHN & 13 & 371 & $150,300,600$ \\
\hline Liu et al $2017^{30}$ (NCT0I455428) & PHN & 8 & 220 & 300 \\
\hline van Seventer et al $2010^{31}$ (NCT00292188) & PT pNeP & 8 & 254 & $150-600$ \\
\hline Markman et al $2018^{32}$ (NCTOI70I362) & PT pNeP & 15 & 539 & $150-600$ \\
\hline Freynhagen et al $2005^{33}$ & DPN/PHN & 12 & 338 & $150-600,600$ \\
\hline Guan et al 20II ${ }^{34}$ (NCT0030I 223) & DPN/PHN & 8 & 308 & $150-600$ \\
\hline Moon et al $2010^{35}$ (NCTO0I4I219) & $\begin{array}{l}\text { DPN/PHN/PT } \\
\mathrm{pNeP}\end{array}$ & 8 & 240 & $150-600$ \\
\hline Siddall et al $2006^{36}$ & $\mathrm{SCl}$ & 12 & 137 & $150,300,600$ \\
\hline Cardenas et al $2013^{37}$ (NCT00407745) & $\mathrm{SCl}$ & 16 & 219 & $150,300,450,600$ \\
\hline Crofford et al $2005^{38}$ & FM & 8 & 529 & $150,300,450$ \\
\hline Mease et al $2008^{39}$ (NCT00645398) & FM & 13 & 748 & $300,450,600$ \\
\hline Arnold et al $2008^{40}$ (NCT00230776) & FM & 14 & 745 & $300,450,600$ \\
\hline Pauer et al 20II $\mathrm{I}^{41}$ (NCT00333866) & FM & 14 & 736 & $300,450,600$ \\
\hline Roth et al $2012^{42}\left(\right.$ NCT00883740) ${ }^{b}$ & FM & 4 & 119 & 300,450 \\
\hline Ohta et al $2012^{43}$ (NCT00830I67) & FM & 15 & 498 & 300,450 \\
\hline Arnold et al $2015^{44}$ (NCTOI 432236) $^{\mathrm{b}}$ & FM & 6 & 193 & $150-450$ \\
\hline $1008-032$ & CLBP & 7 & 253 & 150,600 \\
\hline $1008-104$ & CLBP & 8 & 406 & $300,450,600$ \\
\hline$|008-03|$ & OA & 12 & 296 & 300,600 \\
\hline Simpson et al $2010^{45}$ (NCT0023214I) & HIV NeP & 14 & 302 & $150,300,600$ \\
\hline Simpson et al $2014^{46}$ (NCTOI0492I7) & HIV NeP & 16 & 375 & $150-600$ \\
\hline
\end{tabular}

Notes: ${ }^{a}$ Number of patients randomized and treated. ${ }^{\text {b}}$ These studies were 2-period, 2-way crossover studies. Only data from period I were included in this analysis. Published references are shown where available. Original study numbers have been used to identify those studies that are not published. ClinicalTrials.gov identifying numbers are shown where available. Historical trials are not required to be registered at ClinicalTrials.gov.

Abbreviations: CLBP, chronic low back pain; DPN, diabetic peripheral neuropathy; FM, fibromyalgia; HIV NeP, neuropathic pain associated with HIV neuropathy; OA, osteoarthritis; PHN, postherpetic neuralgia; PT pNeP, posttraumatic peripheral neuropathic pain; SCl, spinal cord injury.

the severity of reported euphoria events or the relationship to study medication. Events were captured separately for pregabalin and placebo. Most studies were of parallel group design, and incidences of euphoria events were captured throughout the duration of the treatment period. Four studies were of 2period, 2-way crossover design, ${ }^{23,24,42,44}$ and the incidences of 
euphoria events in these studies were captured during the first treatment period only.

\section{Prevalence of euphoria events}

For all of the analyses, all doses of pregabalin treatment (75-600 mg/day, fixed or flexible dosing) were pooled because (i) the number of patients reporting euphoria for a given dose was low (fixed dosing: $75 \mathrm{mg}$ /day $=2$; $150 \mathrm{mg} /$ day $=7 ; 300 \mathrm{mg} /$ day $=62 ; 450 \mathrm{mg} /$ day $=45$; $600 \mathrm{mg} /$ day $=62$; flexible dosing $=31$ ), and (ii) most studies included a dose titration period; therefore, the occurrence of euphoric events may have occurred at a different dose than the randomized dose. The prevalence of reported euphoria events was determined for pregabalin and placebo using data from all identified studies. Prevalence rates were calculated overall and by indication. For the remaining analyses, only studies were included in which euphoria events had been reported ( $n=26$ studies). The time to onset and duration were determined for the reported euphoria events. The number of patients who reported multiple euphoria events was calculated, as was the number of patients in which euphoria events were ongoing at the end of the study.

\section{Pain scores}

For the analysis of pain scores, all indications were grouped together. An 11-point numeric rating scale (NRS, where $0=$ no pain and $10=$ worst possible pain) was used to assess pain. Early pain responses were assessed in pregabalin- and placebo-treated patients who did or did not report euphoria events. These pain responses were classified as: (i) $\mathrm{a} \geq 30 \%$ improvement in mean pain score from baseline for Weeks 1 , 2 , and 3 after treatment initiation; ${ }^{47,48}$ and (ii) a $\geq 1$-point reduction in daily pain score compared with baseline for Days 2-11 after treatment initiation. ${ }^{49}$ Additional pain measures were evaluated only in pregabalin- and placebo-treated patients who reported euphoria events. Mean pain scores were determined before and after the onset of the euphoria events with the day of onset of the event as the cutoff date. Pre-onset data could include baseline scores and the day of onset, when available. Post-onset data were determined for Weeks 1 and 2 after the onset of the event, and excluded the day of onset. The change in mean pain score was also measured from baseline to the days that euphoria events were reported. Change in pain score was calculated as the difference between mean baseline pain score and daily pain score.

\section{Sleep scores}

For the analysis of sleep scores, all indications were grouped together. In studies of patients with DPN, PHN, PT pNeP, DPN/PHN, SCI, and CLBP, sleep was assessed using an 11-point pain-related sleep interference (PRSI) score where $0=$ pain does not interfere with sleep to 10 $=$ pain completely interferes with sleep. In FM and OA studies, sleep was assessed using an 11-point NRS sleep quality score. For 6 of these studies, the NRS was scored from $0=$ best possible sleep to $10=$ worst possible sleep. For 2 of the FM studies, the NRS was scored from 0 $=$ worst possible sleep to $10=$ best possible sleep. Early sleep responses were assessed in pregabalin- and placebotreated patients who did and did not report euphoria events. These responses were classified as a $\geq 30 \%$ improvement from baseline in PRSI or mean sleep quality score for Weeks 1, 2, and 3 after treatment initiation.

\section{Statistical analysis}

Data are descriptive only; no statistical comparisons were made.

\section{Results}

A total of 13,252 patients were included in the analysis. Of these, 8,501 (64.1\%) patients received pregabalin and 4,751 (35.9\%) patients received placebo. Overall, $222(1.7 \%)$ patients reported euphoria events, comprising 209 (2.5\%) with pregabalin and $13(0.3 \%)$ with placebo. The majority of patients were female and aged 18 to 64 years. No notable differences were observed in most demographic characteristics between those who did versus did not experience euphoria events (Table 2). In general, female patients reported euphoria events at a higher prevalence than noneuphoria; however, prevalence of euphoria events in females was comparable between treatment groups (with euphoria: pregabalin [72.2\%] and placebo [69.2\%]; without euphoria: pregabalin [60.0\%] and placebo [56.2\%]). The number of euphoria events in each pregabalin dose group were as follows: $75 \mathrm{mg} /$ day $(\mathrm{n}=2), 150 \mathrm{mg} /$ day $(\mathrm{n}=7), 300 \mathrm{mg} /$ day $(\mathrm{n}=62), 450 \mathrm{mg} /$ day $(\mathrm{n}=45), 600 \mathrm{mg} /$ day $(\mathrm{n}=62)$, flexible dosing $(n=31)$, and placebo $(n=13)$ (Table 2). Prevalence rates of euphoria events by indication are shown in Table 3. For pregabalin, euphoria events varied from $0.5 \%$ in patients with $\mathrm{PT}$ pNeP to $9.3 \%$ in patients with OA. The highest rates occurred in patients with non-NeP conditions. For placebo, prevalence varied from $0 \%$ in patients with $\mathrm{PHN}, \mathrm{PT} \mathrm{pNeP}$, or OA to $1.0 \%$ in patients with CLBP. 


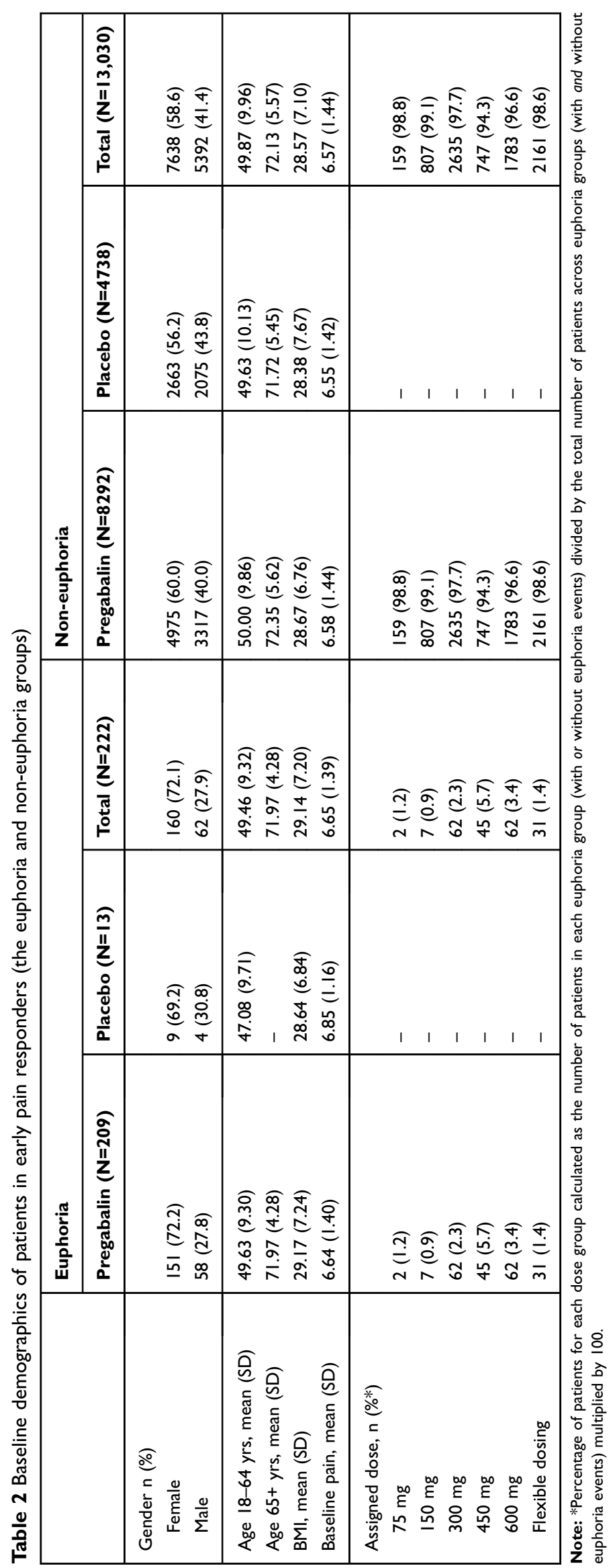


Table 3 Prevalence rates of euphoria events by indication and treatment group

\begin{tabular}{|l|l|l|l|}
\hline Indication & Treatment & $\mathbf{N}$ & $\mathbf{n}(\%)$ \\
\hline DPN & Pregabalin & 2744 & $21(0.8)$ \\
& Placebo & 1645 & $(0.1)$ \\
\hline PHN & Pregabalin & 1649 & $10(0.6)$ \\
& Placebo & 789 & 0 \\
\hline PT pNeP & Pregabalin & 449 & $2(0.5)$ \\
& Placebo & 420 & 0 \\
\hline SCI & Pregabalin & 181 & $4(2.2)$ \\
& Placebo & 175 & $1(0.6)$ \\
\hline FM & Pregabalin & 2474 & $103(4.2)$ \\
& Placebo & 1094 & $6(0.6)$ \\
\hline CLBP & Pregabalin & 466 & $35(7.5)$ \\
& Placebo & 193 & $2(1.0)$ \\
\hline OA & Pregabalin & 204 & $19(9.3)$ \\
& Placebo & 92 & 0 \\
\hline HIV & Pregabalin & 334 & $15(4.5)$ \\
& Placebo & 343 & $2(0.6)$ \\
\hline
\end{tabular}

Notes: $\mathrm{N}=$ number of patients per treatment. $\mathrm{n}(\%)=$ number of patients reporting euphoria events.

Abbreviations: CLBP, chronic low back pain; DPN, diabetic peripheral neuropathy; FM, fibromyalgia; HIV NeP, neuropathic pain associated with HIV neuropathy; $\mathrm{OA}$, osteoarthritis; PHN, postherpetic neuralgia; PT pNeP, posttraumatic peripheral neuropathic pain; $\mathrm{SCl}$, spinal cord injury.

Across all indications, the majority of patients reported only one euphoria event. Eleven patients reported $\geq 2$ events. The median (range) time to the onset of the first event was 2.0 (1-84) days for pregabalin and 2.0 (1-6) days for placebo. The median (range) duration of each event was 10.0 (1-118) days for pregabalin and 3.0 (1121) days for placebo. Twenty-five patients had ongoing euphoria events at the end date of their studies. The duration of euphoria events (using the study end date as censor) ranged from 11-101 days.

The $30 \%$ pain responder rates were compared between pregabalin-treated patients who did and did not report euphoria events (Figure 1). For Weeks 1, 2, and 3 after starting treatment, the proportion of pregabalin-treated patients who were $30 \%$ pain responders was numerically higher in patients who reported (vs those who did not report) euphoria events. Placebo patients showed a similar results for Week 1 with a numerically higher percentage of patients achieving responder status with euphoria events $(30.0 \%$ $[\mathrm{n}=3])$ compared with those with no euphoria events $(8.7 \%$ $[\mathrm{n}=244])$. One placebo patient who was a $30 \%$ pain responder reported a euphoria event in Weeks 2 and 3.

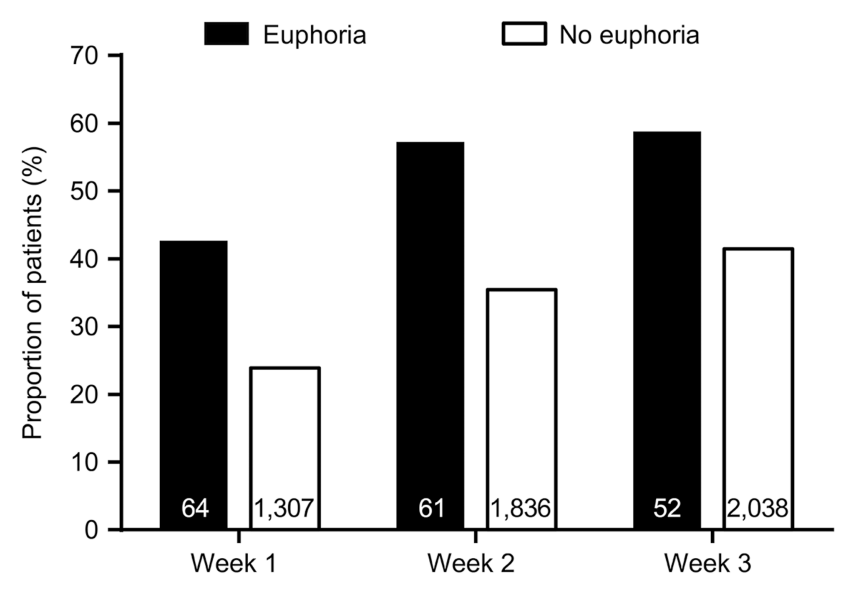

Figure I Proportion of $30 \%$ pain responders in pregabalin-treated patients who did and did not report euphoria events. Patients were classified as $30 \%$ pain responders if they had a $\geq 30 \%$ improvement in pain score (II-point NRS) from baseline. Number of patients who did and did not report euphoria events are shown for each week.

Abbreviation: NRS, numeric rating scale.

Figure 2 shows the comparison of the 1-point pain responder rates in pregabalin-treated patients who did and did not report euphoria events for Days 2-11 after starting treatment. Similar to the $30 \%$ pain responder rate, a numerically higher proportion of pregabalin-treated patients who reported (vs those who did not report) euphoria events were 1-point pain responders for each day. Results for patients who received placebo followed a similar pattern to pregabalin; however, fewer placebo patients were available for analysis (1-5 patients reported euphoria events per day; data not shown).

In patients who reported euphoria events, mean (standard deviation [SD]) pain scores before the onset of the event were numerically similar for pregabalin (6.1 [1.8]) compared with placebo (6.5 [1.9]). For Week 1 after the onset of the event, mean pain scores for pregabalin were numerically lower (4.6 [1.9]) compared with placebo (5.3 [1.9]) suggesting greater pain relief. Findings were similar for Week 2 after the onset of the event (4.4 [2.1] for pregabalin vs 5.3 [2.1] for placebo). The change in mean pain score from baseline was numerically larger for pregabalin versus placebo for the majority of days that euphoria events were reported (Figure 3). The qualitatively greater improvement in mean pain score occurred as early as the first day after starting treatment.

Comparison of the $30 \%$ sleep responder rates in pregabalin-treated patients who did and did not report euphoria events is shown in Figure 4. For Weeks 1, 2, and 3 after starting treatment, the proportion of pregabalin-treated patients who were $30 \%$ sleep responders was numerically 


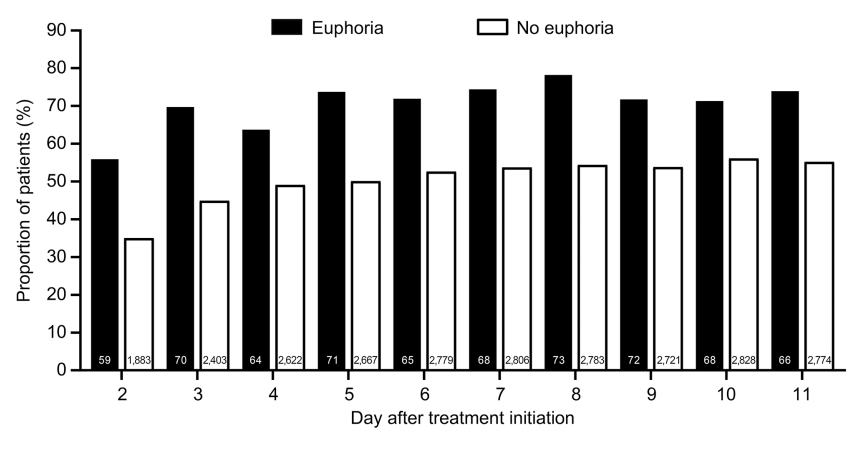

Figure 2 Proportion of I-point pain responders in pregabalin-treated patients who did and did not report euphoria events. Patients were classified as I-point pain responders if they had a $\geq 1$-point improvement in pain score (I I-point NRS) from baseline. The number of patients who did and did not report euphoria events are shown for each day.

Abbreviation: NRS, numeric rating scale.

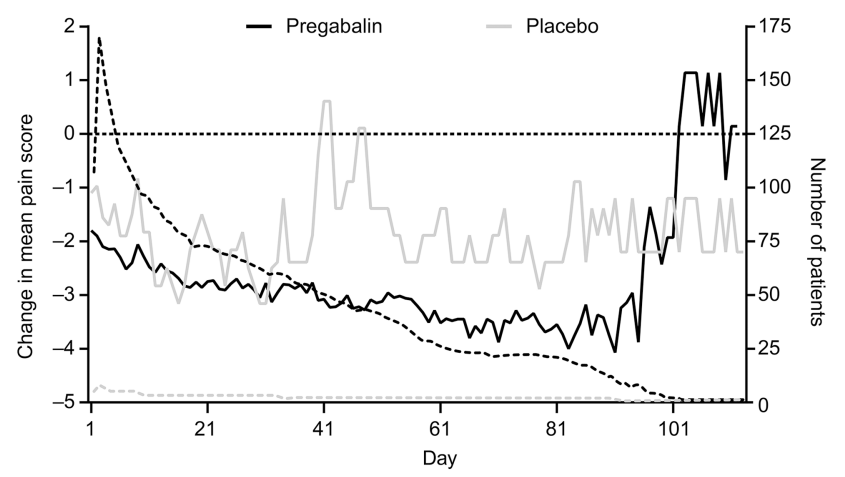

Figure 3 Change in mean pain score from baseline for days euphoria events were reported. Data were determined only in those patients who reported euphoria events. Change in mean pain score was calculated as the difference between baseline pain score and daily pain score for each patient. If no end date of the euphoria event was reported, the last dosing date was used. Solid lines are the change in mean pain scores, dotted lines are the number of patients for each day for each treatment. The horizontal dotted line indicates zero change in mean pain score. Values below zero represent improvements in pain, those above zero represent worsening of pain.

higher in patients who reported (vs those who did not report) euphoria events. This pattern was similar for Weeks 1 and 3 in patients who received placebo (Week 1: euphoria, $30.0 \%[\mathrm{n}=3]$; no euphoria, $13.0 \%$ [n=366]; Week 3: euphoria, $100 \%$ [n=3]; no euphoria, $28.4 \%$ [n=752]). Two placebo patients were $30 \%$ sleep responders who reported euphoria events for Week 2.

\section{Discussion}

In this exploratory post-hoc pooled analysis of clinical trial data for peripheral or central NeP or non-NeP, pregabalintreated patients who reported euphoria events may experience early improvements in pain and sleep. These findings also extend to patients who received placebo, although few placebo-treated patients reported euphoria events limiting the

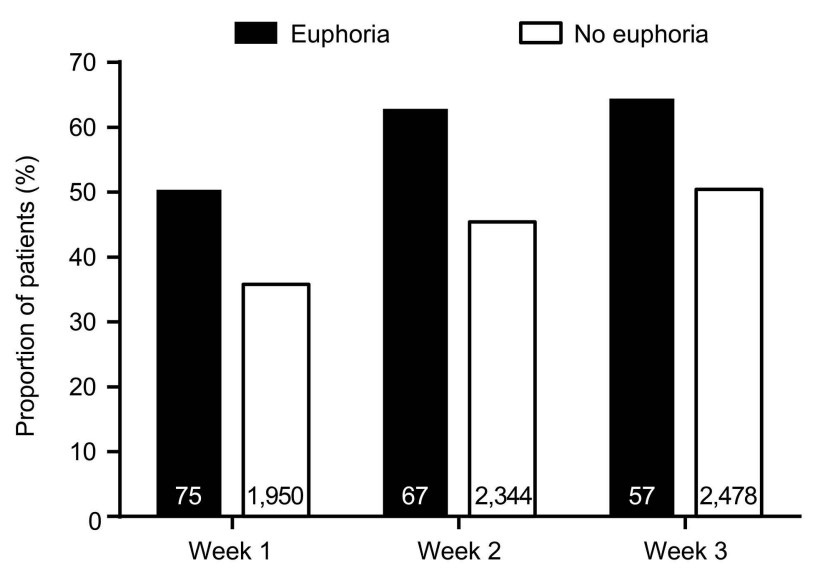

Figure 4 Proportion of 30\% sleep responders in pregabalin-treated patients who did and did not report euphoria events. Patients were classified as $30 \%$ sleep responders if they had a $\geq 30 \%$ improvement in sleep score from baseline. Data from studies that used PRSI or NRS sleep quality score are combined. Number of patients who did and did not report euphoria events are shown for each week. Abbreviations: NRS, numeric rating scale; PRSI, pain-related sleep interference.

ability to draw definitive conclusions. Pregabalin-treated (compared with placebo) patients had numerically greater improvements in pain (absolute and change from baseline) after the onset of the euphoria event. Most of the patients in this analysis were female and in the 18-64 year age group; however there were no notable differences in demographic characteristics between pregabalin and placebo treatment groups. This is in line with a previous pooled analysis of 27 randomized clinical trials that showed that age and sex were among a group of potential predictors of efficacy of pregabalin that had no effect on outcome. ${ }^{50}$

Although this was an exploratory analysis with a relatively small sample of patients who reported euphoria events, this study raises interesting questions about the possible relationship between euphoria and early treatment responses. Patients may be reporting euphoria events because they are experiencing rapid and clinically relevant pain relief and/or sleep improvement after long-standing pain and/or sleep disturbance, respectively. However, we cannot rule out the possibility that patients may report better treatment responses because they have experienced a euphoric event. A causal link between euphoria events and positive treatment responses is difficult to demonstrate, and this study cannot distinguish between these two possibilities. Future research should investigate the potential causal relationship between positive treatment responses and euphoria.

The question of whether treatment-emergent AEs are a direct adverse effect of a study drug, or whether the relationship between reported AEs and active treatment is a more complex interaction, is a difficult question to answer. In a 
pooled analysis of seven randomized controlled studies that examined triptan therapy for migraine attacks, the treatmentemergent AEs somnolence and asthenia were shown to occur due to the unmasking of CNS-related neurological symptoms that were part of the migraine attack, rather than being direct side effects of triptan treatment. ${ }^{51}$ The relationship between treatment-emergent AEs and active treatment may not be as clear-cut as first thought, and is an area for possible future research.

In the US and Europe, up to one-third of individuals have chronic pain, equivalent to $>100$ million people in the US. ${ }^{52-54}$ Chronic pain is a debilitating condition associated with a considerable individual burden. ${ }^{54-56}$ An improvement of 2 points on an 11-point NRS (equivalent to a $30 \%$ improvement) may be considered potentially beneficial. ${ }^{47,48}$ Moreover, pain relief can occur quickly, with estimated times to improvement of pain with pregabalin of 1-2 days for patients with $\mathrm{FM}^{57}$ DPN/PHN, ${ }^{49}$ or NeP due to SCI. ${ }^{58}$ For pregabalin-treated patients who reported euphoria in these analyses, the time to onset of pain relief is similar to the median time to onset of euphoria events (2.0 days). The improvements in sleep in patients who reported euphoria events mirrored the improvements in pain. This finding may not be surprising because the majority of studies in this pooled analyses evaluated PRSI, a measure of how much pain interfered with sleep. However, the findings here reinforce how closely connected pain and sleep are in patients with NeP or non-NeP conditions. Path analysis (a method used to assess direct and indirect contributions of individual variables to efficacy outcomes) has suggested that a considerable proportion ( $\sim 60-80 \%)$ of the improvements in pain seen with pregabalin in patients with DPN or PHN are due to indirect improvements in sleep. ${ }^{59}$ Moreover, in patients with $\mathrm{FM}^{57}{ }^{5 \mathrm{DPN} / \mathrm{PHN}},{ }^{60}$ and NeP due to SCI, ${ }^{58}$ the time to onset of improvements in sleep (1-2 days) are almost identical to the time to onset of pain improvement (1-2 days). ${ }^{49,57,58}$

The relationship between euphoria and the potential abuse of a drug is complex and not fully understood. Reports of euphoria are associated with some centrally acting drugs with no history of abuse. ${ }^{6-8}$ On the other hand, some centrally acting drugs with a well-established history of abuse are not associated with reports of euphoria. ${ }^{9}$ In the US, pregabalin is classified as a Schedule V drug (ie, it has the lowest potential for abuse compared with other controlled [Schedules I to IV] substances). ${ }^{61}$ Nonetheless, reports have been made of pregabalin misuse and abuse. ${ }^{62,63}$ One factor that may affect whether individual patients may misuse or abuse pregabalin is previous substance abuse. ${ }^{63,64}$ The US Prescribing Information and European Summary of Product
Characteristics both state that patients should be carefully evaluated for history of drug abuse and observed for signs of pregabalin misuse or abuse. ${ }^{10,15}$ The findings from the current study should be viewed in light of reports of misuse and abuse of pregabalin.

This study had several potential limitations. Data are from clinical trials only, although this permits a systematic analysis of available data using defined terms. Additional reports of euphoria events may have occurred through ongoing postmarketing pharmacovigilance efforts, but collection of these data may not have been as rigorous as in clinical trials and efficacy outcomes would not necessarily have been captured in postmarketing reports. Moreover, participants in clinical studies are restricted to those who meet inclusion and exclusion criteria resulting in a relatively more homogeneous study population compared with the heterogeneous patients in real world postmarketing data. In addition, only chronic pain indications were evaluated, and other non-pain indications (eg, GAD or partial onset seizures) were not included in the analysis and this study thus cannot draw conclusions on potential efficacy and euphoria interactions in those populations. Relatively few euphoria events were reported with pregabalin, and even fewer with placebo. Because of this, individual indications could not be analyzed separately and individual pregabalin doses had to be pooled. Discerning the potential euphoric effects and efficacy by dose or by individual therapeutic indication would need to occur in a future study. No statistical comparisons were made because this was an exploratory analysis and few patients reported euphoria events limiting the statistical power for an inferential analysis. Thus, all results are intended to be interpreted qualitatively and do not support any causal or statistically significant relationships.

\section{Conclusion}

In summary, the reports of euphoria events in these clinical trials may be related to early treatment responses in some pregabalin-treated patients with chronic pain. More studies are needed to explore the relationship between the euphoria events and pregabalin treatment responses for non-pain indications. These data may also help to inform the design of future clinical trials of analgesics and other centrally acting drugs.

\section{Data sharing statement}

Upon request, and subject to certain criteria, conditions and exceptions (see https://www.pfizer.com/science/clini 
cal-trials/trial-data-and-results for more information), Pfizer will provide access to individual de-identified participant data from Pfizer-sponsored global interventional clinical studies conducted for medicines, vaccines and medical devices (1) for indications that have been approved in the US and/or EU or (2) in programs that have been terminated (ie, development for all indications has been discontinued). Pfizer will also consider requests for the protocol, data dictionary, and statistical analysis plan. Data may be requested from Pfizer trials 24 months after study completion. The de-identified participant data will be made available to researchers whose proposals meet the research criteria and other conditions, and for which an exception does not apply, via a secure portal. To gain access, data requestors must enter into a data access agreement with Pfizer.

\section{Acknowledgments}

We thank Regina Behar from Pfizer for comments on a previous version of the manuscript. Medical writing support was provided by David Cope $\mathrm{PhD}$, of Engage Scientific Solutions. This study was sponsored by Pfizer.

\section{Disclosure}

RF reports consultancy and speaker fees in the past 2 years from AOP Orphan Pharmaceuticals, Eli Lilly, Grünenthal, Merck Selbstmedikation, Mitsubishi Tanabe Pharma, Pfizer Inc., and Scilex Pharmaceuticals, outside of the submitted work. SS is an employee of the University of Western Australia (UWA); within the last 2 years his employer has received honoraria, consulting fees and travel support from Andros Pharmaceuticals, Aspen, bioCSL, Eli Lilly, Grünenthal, Invidior, Janssen, Luye Pharma, Mundipharma, Pfizer Inc., Pierre Fabre, Seqirus, and iX Biopharma. BP, EW, $\mathrm{MO}, \mathrm{PBB}$, and LK are employees of Pfizer and have stock or stock options with Pfizer. The authors report no other conflicts of interest in this work.

\section{References}

1. de Wit H, Phillips TJ. Do initial responses to drugs predict future use or abuse? Neurosci Biobehav Rev. 2012;36(6):1565-1576. doi:10.1016/j.neubiorev.2012.04.005

2. Mansbach RS, Schoedel KA, Kittrelle JP, Sellers EM. The role of adverse events and related safety data in the pre-market evaluation of drug abuse potential. Drug Alcohol Depend. 2010;112(3):173-177. doi:10.1016/j.drugalcdep.2010.07.001

3. O'Connor AB, Turk DC, Dworkin RH, et al. Abuse liability measures for use in analgesic clinical trials in patients with pain: IMMPACT recommendations. Pain. 2013;154(11):2324-2334. doi:10.1016/j. pain.2013.06.035
4. Wise RA, Koob GF. The development and maintenance of drug addiction. Neuropsychopharmacology. 2014;39(2):254-262. doi:10.1038/ npp.2013.261

5. Voon P, Kerr T. "Nonmedical" prescription opioid use in North America: a call for priority action. Subst Abuse Treat Prev Policy. 2013;8:39. doi:10.1186/1747-597X-8-39

6. Pfizer Inc [Internet]. Zoloft ${ }^{\circledR}$ Prescribing Information. New York, NY: Pfizer Inc; 2017. Available from: http://labeling.pfizer.com/ ShowLabeling.aspx?id=517\#page=1. Accessed March 15, 2017.

7. Lilly USA, LLC [Internet]. Prozac ${ }^{\circledR}$ Prescribing Information. Indianapolis, IN: Lilly USA, LLC; 2016. Available from: http://pi. lilly.com/us/prozac.pdf. Accessed March 15, 2017.

8. Horizon Pharma USA, Inc [Internet]. Rayos ${ }^{\circledR}$ Prescribing Information. Deerfield IL: Horizon Pharma USA, Inc; 2016. Available from: http://www.rayosrx.com/pi/RAYOS-PrescribingInformation.pdf. Accessed March 15, 2017.

9. Pfizer Inc [Internet]. Xanax ${ }^{\circledR}$ Prescribing Information. New York, NY: Pfizer Inc; 2016. Available from: http://labeling.pfizer.com/ ShowLabeling.aspx?id=547. Accessed July 08, 2019.

10. Pfizer Inc [Internet]. Lyrica ${ }^{\circledR}$ Prescribing Information. New York, NY: Pfizer Inc; 2016. Available from: http://labeling.pfizer.com/ ShowLabeling.aspx?id=561. Accessed March 15, 2017

11. Field MJ, Cox PJ, Stott E, et al. Identification of the alpha2-delta-1 subunit of voltage-dependent calcium channels as a molecular target for pain mediating the analgesic actions of pregabalin. Proc Natl Acad Sci U S A. 2006;103(46):17537-17542. doi:10.1073/pnas.0 409066103

12. Li Z, Taylor CP, Weber M, et al. Pregabalin is a potent and selective ligand for alpha(2)delta-1 and alpha(2)delta-2 calcium channel subunits. Eur $J$ Pharmacol. 2011;667(1-3):80-90. doi:10.1016/j. ejphar.2011.05.054

13. Mico JA, Prieto R. Elucidating the mechanism of action of pregabalin: alpha(2)delta as a therapeutic target in anxiety. CNS Drugs. 2012;26(8):637-648. doi:10.2165/11634510-000000000-00000

14. Taylor CP, Angelotti T, Fauman E. Pharmacology and mechanism of action of pregabalin: the calcium channel alpha2-delta (alpha2-delta) subunit as a target for antiepileptic drug discovery. Epilepsy Res. 2007;73(2):137-150. doi:10.1016/j.eplepsyres.2006.09.008

15. Pfizer Ltd [Internet]. Lyrica ${ }^{\circledR}$ Summary of Product Characteristics. Sandwich, UK: Pfizer Ltd; 2016. Available from: http://www.ema. europa.eu/docs/en_GB/document_library/EPAR__Product_Information/ human/000546/WC500046602.pdf. Accessed March 15, 2017.

16. Richter RW, Portenoy R, Sharma U, Lamoreaux L, Bockbrader H, Knapp LE. Relief of painful diabetic peripheral neuropathy with pregabalin: a randomized, placebo-controlled trial. J Pain. 2005;6 (4):253-260. doi:10.1016/j.jpain.2004.12.007

17. Lesser H, Sharma U, LaMoreaux L, Poole RM. Pregabalin relieves symptoms of painful diabetic neuropathy: a randomized controlled trial. Neurology. 2004;63(11):2104-2110. doi:10.1212/01.wnl.000014 5767.36287.a1

18. Rosenstock J, Tuchman M, LaMoreaux L, Sharma U. Pregabalin for the treatment of painful diabetic peripheral neuropathy: a doubleblind, placebo-controlled trial. Pain. 2004;110(3):628-638. doi:10.1016/j.pain.2004.05.001

19. Tölle T, Freynhagen R, Versavel M, Trostmann U, Young JP Jr. Pregabalin for relief of neuropathic pain associated with diabetic neuropathy: a randomized, double-blind study. Eur J Pain. 2008;12 (2):203-213. doi:10.1016/j.ejpain.2007.05.003

20. Arezzo JC, Rosenstock J, Lamoreaux L, Pauer L. Efficacy and safety of pregabalin $600 \mathrm{mg} / \mathrm{d}$ for treating painful diabetic peripheral neuropathy: a double-blind placebo-controlled trial. BMC Neurol. 2008;8:33. doi:10.1186/1471-2377-8-33

21. Satoh J, Yagihashi S, Baba M, et al. Efficacy and safety of pregabalin for treating neuropathic pain associated with diabetic peripheral neuropathy: a 14 week, randomized, double-blind, placebo-controlled trial. Diabet Med. 2011;28(1):109-116. doi:10.1111/j.1464-5491.2010.03152.x 
22. Mu Y, Liu X, Li Q, et al. Efficacy and safety of pregabalin for painful diabetic peripheral neuropathy in a population of Chinese patients: A randomized placebo-controlled trial. J Diabetes. 2018;10(3):256265. doi:10.1111/1753-0407.12585

23. Raskin P, Huffman C, Yurkewicz L, et al. Pregabalin in patients with painful diabetic peripheral neuropathy using an NSAID for other pain conditions: a double-blind crossover study. Clin J Pain. 2016;32 (3):203-210. doi:10.1097/AJP.0000000000000254

24. Huffman C, Stacey BR, Tuchman M, et al. Efficacy and safety of pregabalin in the treatment of patients with painful diabetic peripheral neuropathy and pain on walking. Clin J Pain. 2015;31(11):946958. doi:10.1097/AJP.0000000000000198

25. Sabatowski R, Galvez R, Cherry DA, et al. Pregabalin reduces pain and improves sleep and mood disturbances in patients with post-herpetic neuralgia: results of a randomised, placebo-controlled clinical trial. Pain. 2004;109(1-2):26-35. doi:10.1016/j. pain.2004.01.001

26. Dworkin RH, Corbin AE, Young JP Jr., et al. Pregabalin for the treatment of postherpetic neuralgia: a randomized, placebo-controlled trial. Neurology. 2003;60(8):1274-1283. doi:10.1212/01.wnl.000 0055433.55136 .55

27. van Seventer R, Feister HA, Young JP Jr, Stoker M, Versavel M, Rigaudy L. Efficacy and tolerability of twice-daily pregabalin for treating pain and related sleep interference in postherpetic neuralgia: a 13-week, randomized trial. Curr Med Res Opin. 2006;22(2):375384. doi:10.1185/030079906X80404

28. Stacey BR, Barrett JA, Whalen E, Phillips KF, Rowbotham MC. Pregabalin for postherpetic neuralgia: placebo-controlled trial of fixed and flexible dosing regimens on allodynia and time to onset of pain relief. J Pain. 2008;9(11):1006-1017. doi:10.1016/j.jpain.2008.05.014

29. Ogawa S, Suzuki M, Arakawa A, Araki S, Yoshiyama T. Efficacy and tolerability of pregabalin for postherpetic neuralgia: a multicenter, randomized, double-blind, placebo-controlled clinical trial. J Jpn Soc Pain Clin. 2010;17:141-152.

30. Liu Q, Chen H, Xi L, et al. A randomized, double-blind, placebocontrolled trial to evaluate the efficacy and safety of pregabalin for postherpetic neuralgia in a population of chinese patients. Pain Pract. 2017;17(1):62-69. doi:10.1111/papr.12413

31. van Seventer R, Bach FW, Toth CC, et al. Pregabalin in the treatment of post-traumatic peripheral neuropathic pain: a randomized doubleblind trial. Eur J Neurol. 2010;17(8):1082-1089. doi:10.1111/j.14681331.2010.02979.x

32. Markman J, Resnick M, Greenburg S, et al. Efficacy of pregabalin in post-traumatic peripheral neuropathic pain: a randomized, doubleblind, placebo-controlled phase 3 trial. J Neurol. 2018;265 (12):2815-2824. doi:10.1007/s00415-018-9063-9

33. Freynhagen R, Strojek K, Griesing T, Whalen E, Balkenohl M. Efficacy of pregabalin in neuropathic pain evaluated in a 12-week, randomised, double-blind, multicentre, placebo-controlled trial of flexible- and fixed-dose regimens. Pain. 2005;115(3):254-263. doi:10.1016/j.pain.2005.02.032

34. Guan Y, Ding X, Cheng Y, et al. Efficacy of pregabalin for peripheral neuropathic pain: results of an 8-week, flexible-dose, double-blind, placebo-controlled study conducted in China. Clin Ther. 2011;33 (2):159-166. doi:10.1016/j.clinthera.2011.02.007

35. Moon DE, Lee DI, Lee SC, et al. Efficacy and tolerability of pregabalin using a flexible, optimized dose schedule in Korean patients with peripheral neuropathic pain: a 10-week, randomized, doubleblind, placebo-controlled, multicenter study. Clin Ther. 2010;32 (14):2370-2385. doi:10.1016/j.clinthera.2011.01.014

36. Siddall PJ, Cousins MJ, Otte A, Griesing T, Chambers R, Murphy TK. Pregabalin in central neuropathic pain associated with spinal cord injury: a placebo-controlled trial. Neurology. 2006;67 (10):1792-1800. doi:10.1212/01.wnl.0000244422.45278.ff
37. Cardenas DD, Nieshoff EC, Suda K, et al. A randomized trial of pregabalin in patients with neuropathic pain due to spinal cord injury. Neurology. 2013;80(6):533-539. doi:10.1212/WNL.0b013e318 $281546 \mathrm{~b}$

38. Crofford LJ, Rowbotham MC, Mease PJ, et al. Pregabalin for the treatment of fibromyalgia syndrome: results of a randomized, doubleblind, placebo-controlled trial. Arthritis Rheum. 2005;52(4):12641273. doi:10.1002/art.20983

39. Mease PJ, Russell IJ, Arnold LM, et al. A randomized, double-blind, placebo-controlled, phase III trial of pregabalin in the treatment of patients with fibromyalgia. $J$ Rheumatol. 2008;35(3):502-514.

40. Arnold LM, Russell IJ, Diri EW, et al. A 14-week, randomized, double-blinded, placebo-controlled monotherapy trial of pregabalin in patients with fibromyalgia. $J$ Pain. 2008;9(9):792-805. doi:10.1016/j.jpain.2008.03.013

41. Pauer L, Winkelmann A, Arsenault P, et al. An international, randomized, double-blind, placebo-controlled, phase III trial of pregabalin monotherapy in treatment of patients with fibromyalgia. $J$ Rheumatol. 2011;38(12):2643-2652. doi:10.3899/jrheum.110569

42. Roth T, Lankford DA, Bhadra P, Whalen E, Resnick EM. Effect of pregabalin on sleep in patients with fibromyalgia and sleep maintenance disturbance: a randomized, placebo-controlled, 2-way crossover polysomnography study. Arthritis Care Res (Hoboken). 2012;64 (4):597-606. doi:10.1002/acr.21595

43. Ohta H, Oka H, Usui C, Ohkura M, Suzuki M, Nishioka K. A randomized, double-blind, multicenter, placebo-controlled phase III trial to evaluate the efficacy and safety of pregabalin in Japanese patients with fibromyalgia. Arthritis Res Ther. 2012;14(5):R217. doi: $10.1186 /$ ar 4056

44. Arnold LM, Sarzi-Puttini P, Arsenault P, et al. Efficacy and safety of pregabalin in patients with fibromyalgia and comorbid depression taking concurrent antidepressant medication: a randomized, placebo-controlled study. $J$ Rheumatol. 2015;42(7):1237-1244. doi:10.3899/jrheum.141196

45. Simpson DM, Schifitto G, Clifford DB, et al. Pregabalin for painful HIV neuropathy: a randomized, double-blind, placebo-controlled trial. Neurology. 2010;74(5):413-420. doi:10.1212/WNL.0b013e3 $181 \mathrm{ccc} 6 \mathrm{ef}$

46. Simpson DM, Rice AS, Emir B, et al. A randomized, double-blind, placebo-controlled trial and open-label extension study to evaluate the efficacy and safety of pregabalin in the treatment of neuropathic pain associated with human immunodeficiency virus neuropathy. Pain. 2014;155(10):1943-1954. doi:10.1016/j.pain.2014.05.027

47. Dworkin RH, Turk DC, Wyrwich KW, et al. Interpreting the clinical importance of treatment outcomes in chronic pain clinical trials: IMMPACT recommendations. $J$ Pain. 2008;9(2):105-121. doi:10.1016/j.jpain.2007.09.005

48. Farrar JT, Young JP Jr., LaMoreaux L, Werth JL, Poole RM. Clinical importance of changes in chronic pain intensity measured on an 11point numerical pain rating scale. Pain. 2001;94(2):149-158.

49. Sharma U, Griesing T, Emir B, Young JP Jr. Time to onset of neuropathic pain reduction: a retrospective analysis of data from nine controlled trials of pregabalin for painful diabetic peripheral neuropathy and postherpetic neuralgia. Am J Ther. 2010;17(6):577585. doi:10.1097/MJT.0b013e3181d5e4f3

50. Almas M, Parsons B, Whalen E. Prediction of therapeutic response to pregabalin in subjects with neuropathic pain. Curr Med Res Opin. 2018;34(12):2041-2052. doi:10.1080/03007995.2018.1520694

51. Goadsby PJ, Dodick DW, Almas M, et al. Treatment-emergent CNS symptoms following triptan therapy are part of the attack. Cephalalgia. 2007;27(3):254-262. doi:10.1111/j.1468-2982.2007.01278.x

52. Institute of Medicine (IOM). Relieving Pain in America: A Blueprint for Transforming Prevention, Care, Education, and Research. Washington, DC: The National Academies Press; 2011. 
53. Johannes CB, Le TK, Zhou X, Johnston JA, Dworkin RH. The prevalence of chronic pain in United States adults: results of an Internet-based survey. J Pain. 2010;11(11):1230-1239. doi:10.1016/ j.jpain.2010.07.002

54. Breivik H, Eisenberg E, O’Brien T. The individual and societal burden of chronic pain in Europe: the case for strategic prioritisation and action to improve knowledge and availability of appropriate care. BMC Public Health. 2013;13:1229. doi:10.1186/1471-2458-13-1229

55. Breivik H, Collett B, Ventafridda V, Cohen R, Gallacher D. Survey of chronic pain in Europe: prevalence, impact on daily life, and treatment Eur J Pain. 2006;10(4):287-333. doi:10.1016/j.ejpain.2005.06.009

56. Moore RA, Derry S, Taylor RS, Straube S, Phillips CJ. The costs and consequences of adequately managed chronic non-cancer pain and chronic neuropathic pain. Pain Pract. 2014;14(1):79-94. doi:10.1111/papr.12050

57. Arnold LM, Emir B, Pauer L, Resnick M, Clair A. Time to improvement of pain and sleep quality in clinical trials of pregabalin for the treatment of fibromyalgia. Pain Med. 2015;16(1):176-185. doi:10.11 11/pme. 12636

58. Cardenas DD, Emir B, Parsons B. Examining the time to therapeutic effect of pregabalin in spinal cord injury patients with neuropathic pain. Clin Ther. 2015;37(5):1081-1090. doi:10.1016/j.clinthera.2015. 02.028
59. Vinik A, Emir B, Parsons B, Cheung R. Prediction of pregabalinmediated pain response by severity of sleep disturbance in patients with painful diabetic neuropathy and post-herpetic neuralgia. Pain Med. 2014;15(4):661-670. doi:10.1111/pme.12310

60. Parsons B, Emir B, Knapp L. Examining the time to improvement of sleep interference with pregabalin in patients with painful diabetic peripheral neuropathy and postherpetic neuralgia. Am J Ther. 2015;22 (4):257-268. doi:10.1097/MJT.0000000000000100

61. Drug Enforcement Administration. Schedules of controlled substances: placement of pregabalin into schedule V. Final rule. Fed Regist. 2005;70(144):43633-43635.

62. Evoy KE, Morrison MD, Saklad SR. Abuse and misuse of pregabalin and gabapentin. Drugs. 2017;77(4):403-426. doi:10.1007/s40265017-0700-x

63. Schjerning O, Rosenzweig M, Pottegard A, Damkier P, Nielsen J. Abuse potential of pregabalin: a systematic review. CNS Drugs. 2016;30(1):9-25. doi:10.1007/s40263-015-0303-6

64. Schifano F, D'Offizi S, Piccione $M$, et al. Is there a recreational misuse potential for pregabalin? Analysis of anecdotal online reports in comparison with related gabapentin and clonazepam data. Psychother Psychosom. 2011;80(2):118-122. doi:10.1159/000321079
Journal of Pain Research

\section{Publish your work in this journal}

The Journal of Pain Research is an international, peer reviewed, open access, online journal that welcomes laboratory and clinical findings in the fields of pain research and the prevention and management of pain. Original research, reviews, symposium reports, hypothesis formation and commentaries are all considered for publication. The manuscript management system is completely online and includes a very quick and fair peer-review system, which is all easy to use. Visit http:// www.dovepress.com/testimonials.php to read real quotes from published authors. 